THE AMERICAN JOURNAL OF MEDICAL SCIENCES AND PHARMACEUTICAL RESEARCH

[Volume-II Issue-II]

http://usajournalshub.com/index.php/TAJMSPR

IMPACT FACTOR 2019 (4.94)

[Pages $=$ XXIII-XXIX] [2020]

ISSN (e): 2689-1026

IMPACT FACTOR 2020(5.286)

\title{
Coexistence Of Postural Tachycardia Syndrome And Vasovagal Syncope In The Same Patient.
}

Crossref doi:- https://doi.org/10.37547/tajiir/Volume02issue02-02

Amin Ahminedache ${ }^{1}$, Saeed Hatem ${ }^{2}$, Halima Benjelloun ${ }^{1}$, Mohammed Cherti ${ }^{2}$.

1. Cardiology A Department, Avicenna University Hospital,

Rue Lamfedal Cherkaoui, 10.000 Rabat, Morocco

2. Cardiology B Department, Maternité Souissi,

Boulevard Ibn Rochd, Agdal-Hay Ryad 10.000 Rabat, Morocco

Corresponding Author:

Amin Ahminedache, M.D,

Cardiology A Department, Avicenna University Hospital, Rabat, Morocco.

Address: Cardiology A Department, Avicenna University Hospital, Rue Lamfedal Cherkaoui, 10.000 Rabat, Morocco

\begin{abstract}
Postural tachycardia syndrome (PoTS) and vasovagal syncope (VVS) are two prevalent dysautonomic forms of orthostatic intolerance that are linked respectively to a sympathetic hyperactivity and a vagal hyperactivity, but yet, both forms may coexist in the same patient. The mechanism of this association is not well known and the number of published cases remains small to draw management guidelines. We report a case of a healthy 25 years old male who met diagnostic criteria for both PoTS and VVS and who was successfully treated by combining pharmacological and non-pharmacological treatments. We hypothesize through the results of autonomous nervous system (ANS) testing that VVS may be a complication of PoTS through Bezold Jarisch reflex and that the control of PoTS would prevent VVS. Physicians need to be aware of orthostatic intolerance syndromes and resort to ANS tests in patients with a fully normal cardiac workup.
\end{abstract}

KEYWORDS: Postural tachycardia syndrome, vasovagal syncope, Bezold Jarisch reflex.

Amin Ahminedache ${ }^{1}$, Saeed Hatem ${ }^{2}$, Halima Benjelloun ${ }^{1}$, Mohammed Cherti ${ }^{2}$, Page XXIII

TAJMSPR [Volume- II Issue- II February 2020

[http://usajournalshub.com/index.php/TAJMSPR] 
THE AMERICAN JOURNAL OF MEDICAL SCIENCES AND PHARMACEUTICAL RESEARCH

[Volume-II Issue-II]

http://usajournalshub.com/index.php/TAJMSPR

IMPACT FACTOR 2019 (4.94)

$[$ Pages $=$ XXIII-XXIX] [2020]

ISSN (e): 2689-1026

IMPACT FACTOR 2020(5.286)

\section{INTRODUCTION}

Postural tachycardia syndrome (PoTS) and vasovagal syncope (VVS) are two prevalent dysautonomic forms of orthostatic intolerance that are linked respectively to a sympathetic hyperactivity and a vagal hyperactivity, but yet, both forms may coexist in the same patient. The mechanism

of this association is not well known and the number of published cases remains small to draw management guidelines.

\section{CASE REPORT}

A 25 years old male who works as a policeman guard which requires him to stand still for several hours ranging from 2 to 9 hours, was referred to our autonomic nervous system (ANS) unit for unexplained palpitation and pre-syncope while performing his duty. Nine months before his visit, he started reporting rapid regular palpitations, chest discomfort, dyspnea, weak legs, sweating, lightheadedness, blurred vision, dizziness and a fainting sensation. The symptoms start occurring after 10 minutes of standing and up to 120 minutes. Most of the times symptoms are mild but sometimes they are severe that the patient squats down to avoid fainting. Hot weather and missed meals seem to worsen the symptoms. The patient has no noticeable medical history and denies any infectious episode, emotional or physical trauma before the onset of the symptoms. His cardiac, respiratory and central nervous system examination was normal. His tests including CBC, renal, thyroid function, ECG, 24 hours ECG and echocardiography were normal.

ANS testing results were as follow: Baseline heart rate (HR) at $85 \mathrm{bpm}$ and blood pressure (BP) was 127/76mmHg. Deep breathing test showed an increase in HR from 85 to 105 bpm and a decrease in BP from $124 / 74 \mathrm{mmHg}$ to $119 / 71 \mathrm{mmHg}$. Hyperventilation test showed an increase in HR from 88 to $105 \mathrm{bpm}$ and a decrease in BP from 125/76 $\mathrm{mmHg}$ to $111 / 66 \mathrm{mmHg}$. Hand grip test increased BP from 121/76mmHg to 131/81 mmHg and HR from 90 to $104 \mathrm{bpm}$. Mental stress test increased BP from 116/74 to 125/71mmHg and HR from 86 to $91 \mathrm{bpm}$. Orthostatic Test was performed by an active movement from a supine to an upright position. In the first two minutes BP was changing between 116/76 and 126/80 $\mathrm{mmHg}$ with baseline BP: $115 / 67 \mathrm{mmHg}$, HR increased from 83 to $123 \mathrm{bpm}$. At the end of the third there was a rapid concomitant drop in HR and BP associated with a fainting sensation. We stopped the test at the fourth minute at a HR of 66 
THE AMERICAN JOURNAL OF MEDICAL SCIENCES AND PHARMACEUTICAL RESEARCH

[Volume-II Issue-II]

http://usajournalshub.com/index.php/TAJMSPR

IMPACT FACTOR 2019 (4.94)

$[$ Pages $=$ XXIII-XXIX] [2020]

ISSN (e): 2689-1026

IMPACT FACTOR 2020(5.286)

bpm and BP of $77 / 31 \mathrm{mmHg}$ (Figure 1, Figure 2). Immediately after repositioning the patient in a supine position, BP jumped to $113 / 72$ and HR started increasing. After 10 minutes HR and BP were stable HR: $75 \mathrm{bpm}$ and $116 / 72 \mathrm{mmHg}$ and the patient felt normal. After 10 minutes of rest in a supine position we decided to undertake another orthostatic test which confirmed the results of the first test with an increase of HR of more than 30bpm with no fall in BP within the first two minutes followed by a rapid drop in HR and BP associated with a fainting sensation.

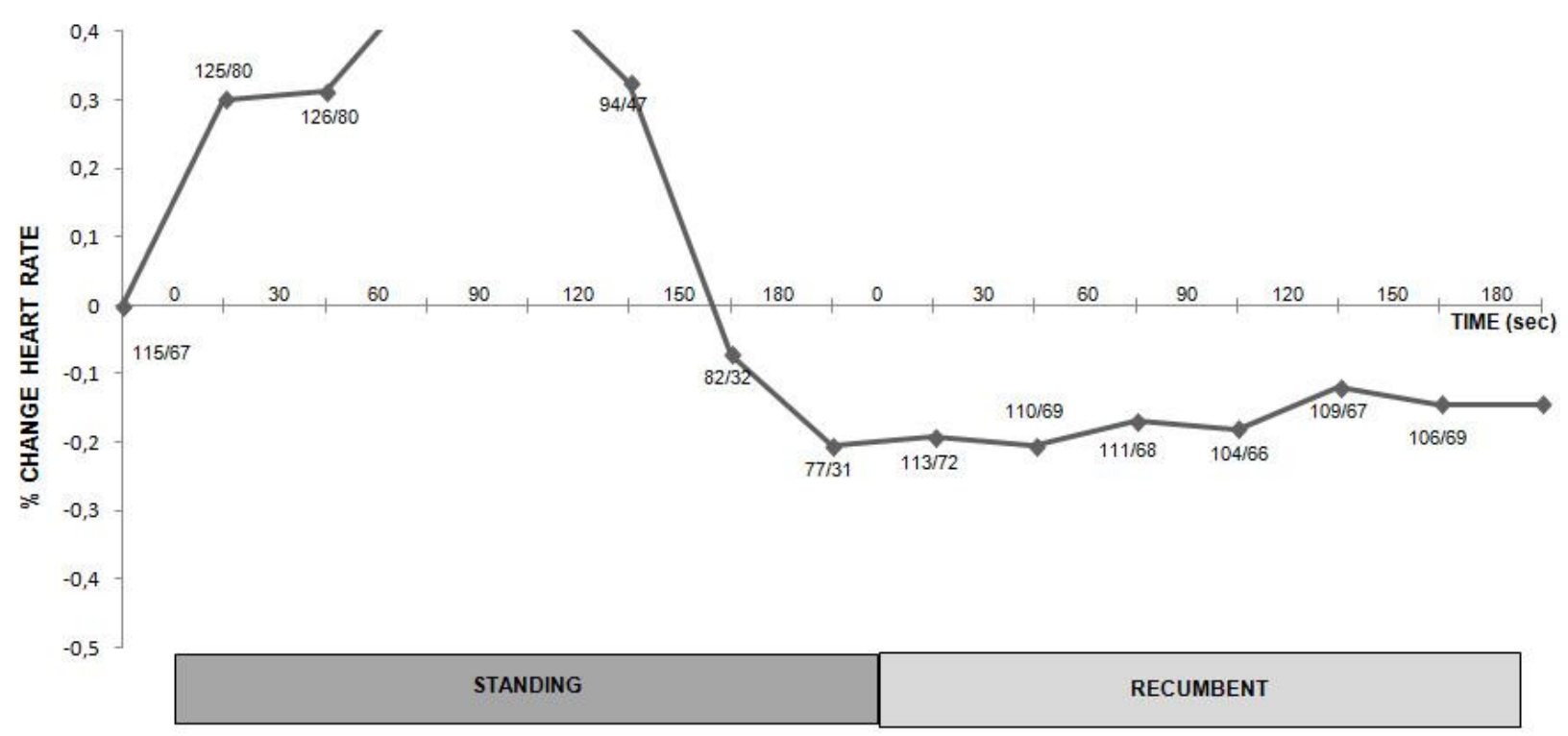

Fig 1 Variation of Heart rate during orthostatic test

As first line therapy the patient was prescribed daily intake of 2 to $3 \mathrm{~L}$ of water, increase of salt intake, waist high support stocking, Heptaminol cholrhydrate 187,8 mg per day, fludrocortisone 0,1mg per day and midodrine 2,5mg bid. After 1 month of no clinical improvement, a low dose of $1.25 \mathrm{mg}$ per day of bisoprolol was introduced resulting in spectacular improvement. For the first month of treatment the patient had a certified full sick-leave then he was on a vocational rehabilitation program as an office assistant. After 6 months of treatment he returned to his work as a guard.

Amin Ahminedache ${ }^{1}$, Saeed Hatem ${ }^{2}$, Halima Benjelloun ${ }^{1}$, Mohammed Cherti ${ }^{2}$, 
THE AMERICAN JOURNAL OF MEDICAL SCIENCES AND PHARMACEUTICAL RESEARCH

[Volume-II Issue-II]

http://usajournalshub.com/index.php/TAJMSPR

IMPACT FACTOR 2019 (4.94)

$[$ Pages $=$ XXIII-XXIX] [2020]

ISSN (e): 2689-1026

IMPACT FACTOR 2020(5.286)

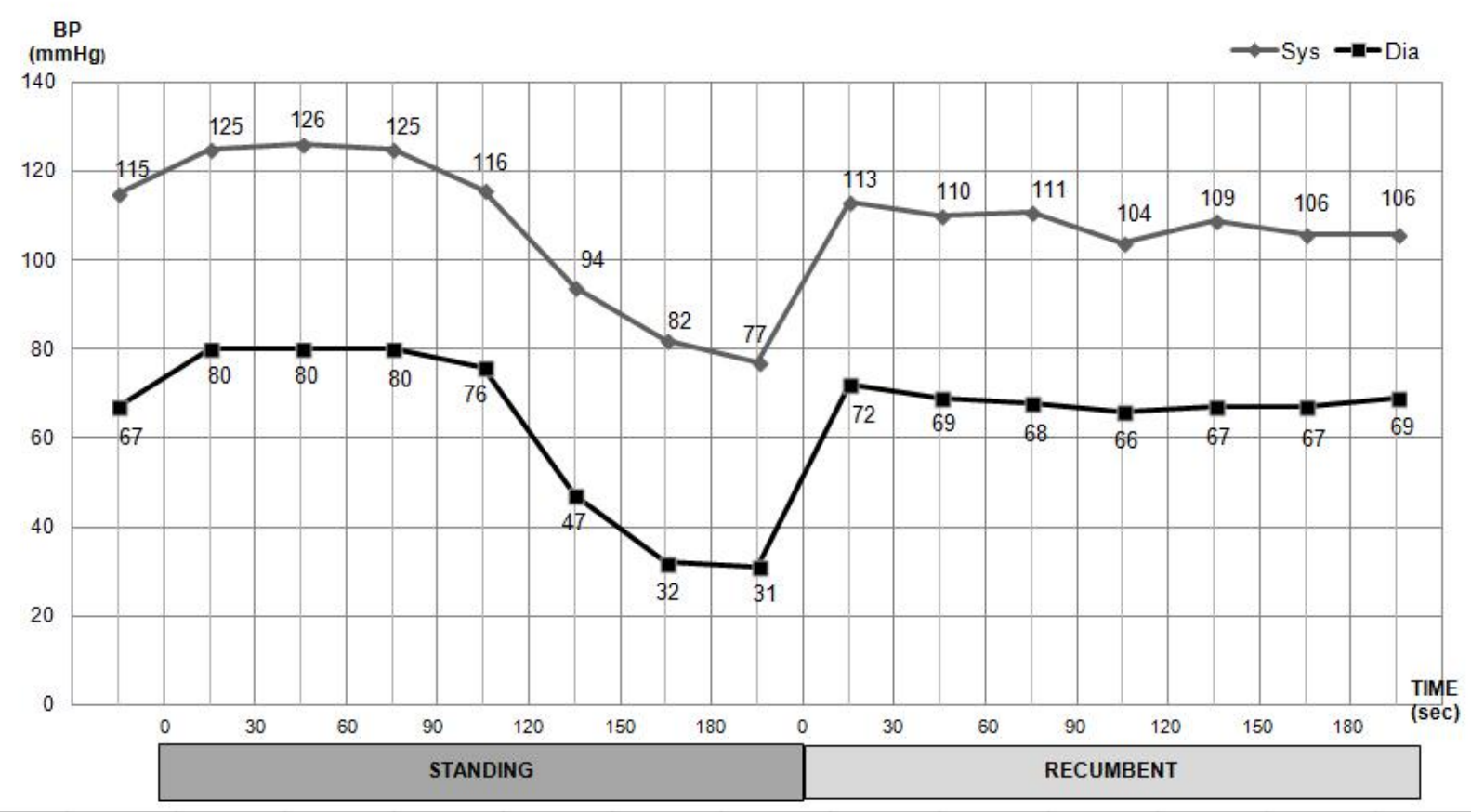

Fig 2 Variation of Blood pressure during orthostatic test

\section{DISCUSSION}

PoTS is the most prevalent dysautonomic disorder affecting around $0.2 \%$ of the general population but this prevalence rate is likely higher due to underdiagnoses [1-4]. PoTS is characterized by frequent orthostatic intolerance symptoms associated with an increase in HR of $30 \mathrm{bpm}$ or more when moving to an upright position held for more than 30 seconds in the absence of orthostatic hypotension (drop in Systolic BP >20 $\mathrm{mmHg}$ ) [1]. Postural tachycardia is the final result of diverse, complex and overlapping physiopathological pathways that all have in common the activation of the sympathetic system as a result of a decrease in venous return [5]. On the other hand, The VVS is characterized by a transient loss of consciousness that occurs with upright posture held for more than 30 seconds associated with hypotension and bradycardia [1] which are the result of a parasympathetic activation that is believed to be the response to a hypercontracile underfilled left ventricle in a similar way to the Bezold Jarisch Reflex [6].

The occurrence of VVS in PoTS patient is a common finding in cardiological daily practice. Our Patients met 
THE AMERICAN JOURNAL OF MEDICAL SCIENCES AND PHARMACEUTICAL RESEARCH

[Volume-II Issue-II]

http://usajournalshub.com/index.php/TAJMSPR

IMPACT FACTOR 2019 (4.94)

$[$ Pages $=$ XXIII-XXIX] [2020]

ISSN (e): 2689-1026

IMPACT FACTOR 2020(5.286)

full criteria of the diagnostic of PoTS and vasovagal presyncope as defined by the 2015 Heart Rhythm Society Expert Consensus [1]. The same consensus reports that both conditions are not mutually exclusive hence can coexist in the same patient [1].This raises the question of how two distinct, if not even opposite physiopathological processes can overlap in the same patient?

The mechanisms responsible for the occurrence of VVS in PoTS patients are complex and not fully elucidated $[7,8]$. In the present case, based on the orthostatic test analysis, we hypothesize that the sympathetic alpha activity was ineffective in restoring adequate venous return by peripheral vasoconstriction which led to venous pooling and underfilling of the left ventricle. Meanwhile, the beta sympathetic hyperactivity increased the inotropy of the empty ventricle to the Bezold-Jarish trigger threshold leading to the activation of the left ventricle sensory receptors resulting in a paradoxical vagal activation and sympathetic inihibition involving a drop in BP and HR.

In the present case, the patient presented a presyncope at the third minute of the orthostatic test while in real life he always presented the symptoms after at least 10 minutes of standing. In a study comparing postural sway in control subjects with good and poor orthostatic tolerance, Claydon [9] has shown that there was a significant negative correlation between postural sway and orthostatic tolerance. Those finding can explain the premature occurrence of symptoms in our patient as patients tend to minimize their leg movements under laboratory testing conditions which alters venous return even further.

The therapeutic strategy in PoTS and VVS remains difficult to be established because of the great variability of the therapeutic response and the occurrence of side effects and also because very few drugs have been studied in randomized clinical trials in PoTS and no drug in the case of association POTS with a VVS. In our autonomous nervous system exploration unit, we use low dose beta blockers as first line drugs in PoTS if the non-pharmacological measures are ineffective, which has resulted in very good functional results. In this case, we have left betablockers in the second line because they haven't shown to be effective in preventing VVS in randomized studies and we have preferred to start with midodrine and fludrocortisone whose effectiveness in the treatment of VVS is supported by randomized studies [10-12] while it is the subject of expert consensus in PoTS. This strategy proved to be ineffective and the patient did not report improvement 
THE AMERICAN JOURNAL OF MEDICAL SCIENCES AND PHARMACEUTICAL RESEARCH

[Volume-II Issue-II]

http://usajournalshub.com/index.php/TAJMSPR

IMPACT FACTOR 2019 (4.94)

$[$ Pages $=$ XXIII-XXIX] [2020]

ISSN (e): 2689-1026

IMPACT FACTOR 2020(5.286)

until low-dose bisoprolol was introduced. The effectiveness of bisoprolol in this case support our hypothesis according to which the vasovagal reflex is triggered by increased inotropy of the left ventricle in the context of an underfilling environment and that VVS is a complication of PoTS rather than a condition that overlaps with PoTS.

\section{CONFLICT OF INTEREST AND SOURCE OF FUNDING:}

The authors declare that they have no conflict of interest.

This research did not receive any specific grant from funding agencies in the public, commercial, or not-forprofit sectors.

\section{REFERENCES}

[1] Sheldon RS, Grubb BP, Olshansky B, Shen WK, Calkins H, Brignole M, Raj SR, Krahn AD, Morillo CA, Stewart JM, Sutton R, Sandroni P, Friday KJ, Hachul DT, Cohen MI, Lau DH, Mayuga KA, Moak JP, Sandhu RK, Kanjwal K. 2015 heart rhythm society expert consensus statement on the diagnosis and treatment of postural tachycardia syndrome, inappropriate sinus tachycardia, and vasovagal syncope. Heart Rhythm. 2015; 12:e41-e63.

[2] Mathias, C. J., Low, D. A., lodice, V., Owens, A. P., Kirbis, M., \& Grahame, R. (2012). "Postural tachycardia syndrome-current experience and concepts". Nat Rev Neurol. 2011 Dec 6;8(1):22-34.

[3] Garland EM, Raj SR, Black BK, Harris PA, Robertson D. The hemodynamic and neurohumoral phenotype of postural tachycardia syndrome. Neurology. 2007; 69:790-798.

[4] Low PA, Sandroni P, Joyner M, Shen WK. Postural tachycardia syndrome (POTS). J Cardiovasc Electrophysiol. 2009; 20:352-358.

[5] Raj SR. The Postural Tachycardia Syndrome (POTS): pathophysiology, diagnosis \& management. Indian Pacing Electrophysiol J. 2006; 6:84-99.

[6] Aviado DM and Guevara AD. The Bezold-Jarisch reflex. A historical perspective of cardiopulmonary reflexes. Ann N Y Acad Sci. 2001. 940:48-58.

Amin Ahminedache ${ }^{1}$, Saeed Hatem ${ }^{2}$, Halima Benjelloun ${ }^{1}$, Mohammed Cherti ${ }^{2}$, 
THE AMERICAN JOURNAL OF MEDICAL SCIENCES AND PHARMACEUTICAL RESEARCH

[Volume-II Issue-II]

http://usajournalshub.com/index.php/TAJMSPR

IMPACT FACTOR 2019 (4.94)

$[$ Pages $=$ XXIII-XXIX] [2020]

ISSN (e): 2689-1026

IMPACT FACTOR 2020(5.286)

[7] Sandroni P, Opfer-Gehrking TL, Benarroch EF, Shen WK, Low PA. Certain cardiovascular indices predict syncope in the postural tachycardia syndrome. Clin Auton Res. 1996 Aug;6(4):225-31

[8] Lambert E, Lambert GW. Sympathetic dysfunction in vasovagal syncope and the postural orthostatic tachycardia syndrome. Front Physiol. 2014 Jul 28;5:280. doi: 10.3389/fphys.2014.00280.

[9] Claydon VE, Hainsworth R. Increased postural sway in control subjects with poor orthostatic tolerance. J Am Coll Cardiol. 2005 Oct 4;46(7):1309-13.

[10] Claydon VE, Hainsworth R. Increased postural sway in control subjects with poor orthostatic tolerance. J Am Coll Cardiol. 2005 Oct 4;46(7):1309-13.

[11] A, Schweikert R, Pavia S, et al. Usefulness of midodrine in patients with severely symptomatic neurocardiogenic syncope: a randomized control study. J Cardiovasc electrophysiol 2001; 12: 935-938

[12] Sheldon R et al. Fludrocortisone for the Prevention of Vasovagal Syncope: A Randomized, PlaceboControlled Trial. J Am Coll Cardiol. 2016 Jul 5;68(1):1-9. doi: 10.1016/j.jacc.2016.04.0

Amin Ahminedache ${ }^{1}$, Saeed Hatem ${ }^{2}$, Halima Benjelloun ${ }^{1}$, Mohammed Cherti ${ }^{2}$, 